\title{
FOCUS ON HEALTHY COMMUNITIES
}

\section{FOREWORD}

\section{fTEALITHY}

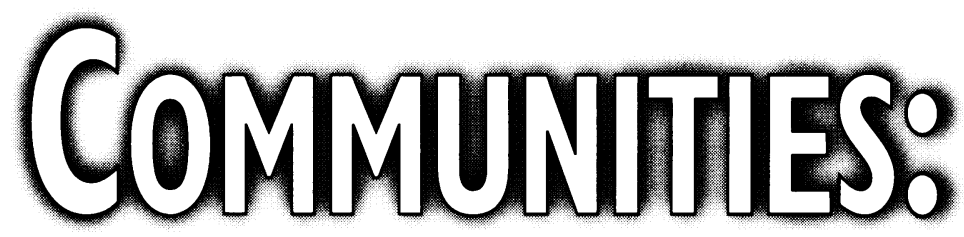

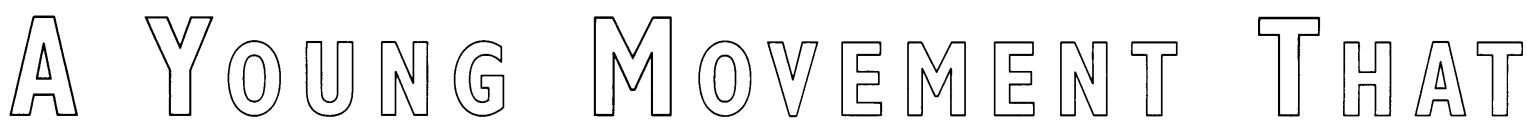

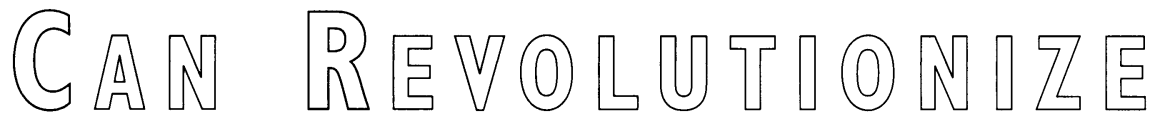

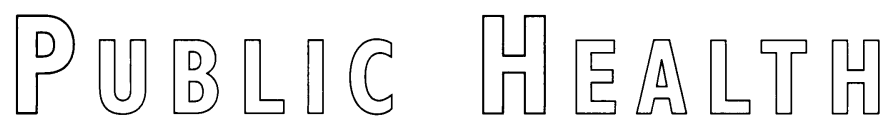

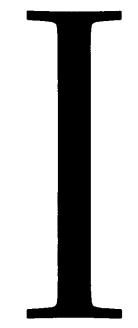

am honored to have been asked by Len Duhl and Judith Kurland to help compile this special focus issue of Public documenting the history, challenges, and accomplishments of the Healthy Communities movement have been slow to enter the professional journals over the last few years. The reasons can be found in the movement's relative youth, the complexity of commu- nity work, and the limited resources of Healthy Communities programs and staff. However, this issue of PHR should put a serious dent into that deficit and, hopefully, stimulate more quality articles in the future.

The Healthy Communities movement in the United States is only 10 years old. It was birthed and has been nurtured at a time of massive upheavals in health/medical care, government, public health, and grassroots/ community movements. Those upheavals have been both a blessing and a "curse" for the movement.

Health care institutions have been leaders in initiating and sustaining the movement in hundreds of 
communities across the country. Without the leadership and funding they have provided directly or through conversion foundations and other community benefits, the movement would not be as widespread as it is.

At the same time, the term Healthy Communities has often been tacked onto community efforts without any regard to the principles the concept embodies because it "sounds good" in the marketing efforts of hospitals, public health agencies, and, yes, even banks. This has led to unrealistic expectations and, at times, dismissal of the movement as a fad because it has not delivered and documented quick and easy solutions to health problems which result from complex community and social problems.

Investing wisely in the Healthy Communities process should involve all of the Healthy Communities principles:

- Broad definition of health.

- Broad definition of community.

- Shared vision from community values.

- Address quality of life for everyone.

- Diverse citizen participation and widespread community ownership.

- Focus on "systems change."

- Build capacity using local assets and resources.

- Benchmark and measure progress and outcomes.

Where we see Healthy Communities initiatives address all of these points, we see strong and sustained efforts that are making change and improving quality of life. Where we see these principles ignored, we see some of the same failed efforts of the past.

Addressing health and quality of life issues today is intensely complex. Our communities are complex. Simple solutions, often the quick "sound-bite" solutions sought in public forums, do not work. Healthy Communities is a slow and deliberate process that builds on local assets and (re)builds trusting relationships between people and institutions. It takes time and is often very messy.

Most practitioners have no extra time or resources to write scholarly articles that document successes and that can persuade institutions to change the way they do business. The experiences and successes of local Healthy Communities efforts, which could provide a richness to our professional literature, are largely untapped.
This issue of Public Health Reports aims to change that. It offers, in part, the history, background, rationale, key components, tools, unique solutions, challenges, and even criticisms of the movement to date. It is my hope that it will stimulate more quality articles that will add substantial depth to this movement.

We need to document the importance of Healthy Communities principles before this movement gets stamped as ineffective. We need to document the relationships of architecture, city planning, and urban design to health improvement. A major contributor of our health problems is sedentary lifestyles, yet we still build our communities so that it can be hard for people to be physically active.

We need articles regarding Healthy Communities and mental health, Healthy Communities and people living with disabilities, Healthy Communities/Safe Communities, neighbors helping neighbors, and the role of community in caregiving now that managed care is pushing caregiving out of hospitals and back to families, faith communities, and neighbors. And we need more articles that explore state and federal roles in supporting and sustaining local efforts.

I am deeply indebted to Joyce Hallenbeck, former Assistant Director of the South Carolina Healthy Communities Initiative, for her initial edit of the documents submitted for publication. Thanks also to Judith Kurland for initiating this special-focus issue of the journal, to Julie Michaels, Jeri Zeder, and Chris Kertesz for their thoughtful editing, and to Judy Kaplan, Mary Fisher, and Naomi Aluf of the journal staff for their support. I am also indebted to the many community members, Healthy Communities workers, and academic, government, public health, and not-forprofit professionals who have submitted the wide array of excellent articles for this publication. I believe you will find their hard work helpful and inspiring.

I look forward to this issue being the first in a series of reports on an important movement built on the very strength of our country in our early years, as noted by de Tocqueville: the strong sense of community and the communitarian ethic. Healthy Communities is, and can be, in my view, the future of public health.

Happy reading and good health. 